\title{
A Survey of JEL Codes: \\ What Do They Mean and Are They Used Consistently?
}

\author{
Lea-Rachel Kosnik ${ }^{1}$
}

UMSL Department of Economics Working Paper \#1011

2016

\author{
Department of Economics \\ 408 SSB \\ University of Missouri - St. Louis \\ 1 University Blvd \\ St. Louis, MO 63121 \\ https://www.umsl.edu/econ/
}

1 University of Missouri-St. Louis, Department of Economics Email: kosnikl@umsl.edu 


\title{
A Survey of JEL Codes: What Do They Mean and Are They Used Consistently?
}

\author{
Lea-Rachel Kosnik \\ Department of Economics \\ University of Missouri-St. Louis \\ St. Louis, MO 63121-4499 \\ Tel: 1-314-516-5564 \\ Fax: 1-314-516-5352 \\ kosnikl@umsl.edu
}

2016 - Draft

\begin{abstract}
The use and prevalence of JEL code categorization is wide in the field of economics, but what do JEL code classifications actually tell us? And are they used with consistency by academics in the field? Utilizing a dataset of articles published in the American Economic Review from 1990-2008, we investigate whether there is heterogeneity in JEL codes assignments between authors and editors. We find that there is. A secondary goal of this paper is to survey overall thematic trends in JEL code usage over the past four and a half decades. One result is that JEL category M: Business Economics, in particular, appears to be thematically and spatially distinct from much of the rest of the published literature in the top general interest journals in the field.
\end{abstract}

JEL Code: A1; B0

Keywords: text analysis, JEL code, economics research, economics literature, thematic analysis

Acknowledgements: Many thanks to Robert Whaples, David Laband, Dan Hamermesh, Stefano DellaVigna, Bob Tollison, Allen Bellas, two anonymous reviewers and seminar participants at the University of Missouri-St. Louis, and the Southern and Midwestern regional economics meetings. 


\section{Introduction}

The use and prevalence of JEL code categorization is wide in the field of economics, but what do JEL code classifications actually tell us? And are they used with consistency by academics in the field? Cherrier (2015) has pointed out in her thorough analysis of the history of JEL code construction that there were often fierce debates within the profession as to what the purpose of the JEL code system was, and how it should be both constructed and subsequently utilized. Do such disagreements continue to have an effect on how JEL codes are assigned today? The first goal of this paper is to analyze a set of papers with both editor-assigned and author-assigned JEL codes and analyze them for significant differences. Understanding JEL code usage is important for many reasons; they are now the standard classification system used by most researchers in the field, JEL codes are prevalent across national and international economics journals and numerous classification databases such as EBSCO and EconLit, and they have been used as input variables in research studies that seek to determine subject focus of academic research (Card and DellaVigna, 2013; Kelly and Bruestle, 2011; Whaples, 1991). This paper tests the standard assumption that JEL codes are used with consistency in classifying papers in the field.

A second goal of this paper is to survey the primary 16 JEL subject categories currently in use, and analyze them for top thematic trends. ${ }^{1}$ What have been the big issues studied in labor, for example, or natural resource economics, over the past four and a half decades, and how have these top foci changed over time? Through a textual analysis of JEL code usage, and an accompanying spatial network analysis of key term frequencies, this paper explores thematic

\footnotetext{
1 There are officially twenty current JEL subject categories, but the first two - "A: General Economics \& Teaching” and "B: History of Economic Thought, Methodology, \& Heterodox Approaches" - and the last two - "Y: Miscellaneous" and "Z: Other Special Topics" - are omitted from this analysis as they are used rather infrequently, making it difficult to run empirical analyses with so few observations.
} 
trends, including which research subjects tend to be investigated together, and which are spatially far apart. Spatial network analysis can highlight well-investigated, nodal areas of economics research, as well as outliers in the field where perhaps more research attention is needed, or where new trends in thought on the edges of the horizon are being developed.

Ultimately, it is important to understand how economists categorize their own research literature, as much can depend on it. If researchers, editors, and authors are using JEL codes disparately, papers may not be indexed correctly and prevalent misinformation could lead to inefficiencies in research access; papers not being read in related thematic categories that should be, and other papers appearing prominently in areas for which they are only tangential. ${ }^{2}$ Cherrier (2015) points out that a vague JEL code system can also be confusing to those outside the field for example to employers, government agencies, or journalists - when they are trying to navigate research output and trends in economics. A thorough JEL code analysis will also highlight, perhaps unrealized top thematic categories studied, and networked areas of research focus and attention. It will give an indication of how the field has been spending its intellectual capital over the past four and a half decades.

\section{Literature Review}

The JEL classification system was developed over one hundred years ago as a method of classifying scholarly literature in the field of economics. ${ }^{3}$ It is now the standard classification system used by most researchers in the field, and JEL codes are prevalent across national and

\footnotetext{
${ }^{2}$ Working paper websites such as SSRN (Social Science Research Network), for example, have search functions based on JEL codes.

${ }^{3}$ This description is taken directly from the JEL classification system webpage:

https://www.aeaweb.org/econlit/jelCodes.php.
} 
international economics journals and numerous classification databases such as EBSCO and EconLit.

JEL codes are used by employers to identify researchers and their work, they are used by journalists to find articles relevant to understanding contemporary policy topics, they are used by online portals to categorize work, and they are often used by academics in the field when trying to categorize and understand the kind of research that gets published in top academic journals (Rath and Wohlrabe, 2015; Grijalva and Nowell, 2014; Card and DellaVigna, 2013; Kelly and Bruestle, 2011; Kim et al., 2006; Durden and Ellis, 1993). While the usefulness of the JEL code classification system is without controversy, analyses of the JEL code classification system itself are rare. Cherrier (2015) has put together a historically insightful look at the behind-the-scenes creation of the JEL code system, including some of the politics and egos that went into its various iterations, but that work is a qualitative historical narrative. ${ }^{4}$ This research is a more quantitative investigation that surveys JEL code usage over time, and whether or not there has been agreement between authors and editors in the utilization of JEL codes assigned to the exact same papers.

The main contributions of this paper are three-fold. First, it investigates whether JEL codes have been used consistently in the field, as represented by JEL code assignations by authors and editors to the very same articles. Second, this research adds to the discussion of economics research trends more broadly by analyzing JEL subject categories themselves and what they have stood for in the top general interest journals in the field since 1969; this is a new angle to the research trends literature. Finally, the analysis includes spatial network and textual analysis, unique methodological tools relatively new to the field, though increasingly popular in

\footnotetext{
${ }^{4}$ If the reader wishes to understand the narrative history of changes to the JEL code, they should refer to that work.
} 
their application (Kosnik, 2015a; Kosnik, 2015b; Baker et al., 2014; Gentzkow and Shapiro, 2010; Tetlock, 2007; Antweiler and Frank, 2004).

\section{Theory}

When an editor (or editorial assistant) assigns a JEL code to a paper, what is her objective? Is she trying to maximize the amount of informational content conveyed by the JEL code classification, and so will use it broadly and assign it liberally? Alternatively, is her goal to accurately reflect a tight understanding of a certain subject category and not allow it to be diluted with only tangentially related research, so that when people search on it, they know what they are getting? Conflicting interpretations of the use of JEL code assignments indeed went into the creation of the original JEL code classification system (Cherrier, 2015), as well as affected its subsequent iterations. Debates were had amongst top researchers in the field as to whether the JEL category codes should be broadly interpreted, or succinctly refined. Some of these debates have never been satisfactorily settled. ${ }^{5}$

Motivations for JEL code usage may also differ by assignee. When an author (as opposed to an editor) assigns a JEL code to her own paper, what is her objective? To identify the paper to its most likely readers, or to broaden its appeal as well as its readership by assigning codes in a more tangential manner? Would the latter lead to more cites and a greater impact on the author's professional reputation?

It is hard to decide a priori which motivation should dominate either editors, or authors. Both face an objective function where they are likely to desire maximization of readership of the article under assignment, but subject to reputation constraints from assigning far-flung JEL codes

\footnotetext{
${ }^{5}$ This may be why the JEL classification system appears to be headed into yet another iteration - see the minutes of the meeting of the Executive Committee, January 2, 2014 at: https://www.aeaweb.org/AboutAEA/meeting_minutes.php
} 
that waste a reader's time. Which effect dominates? In this paper, we compare JEL code assignments by authors and editors, on the very same papers, and test whether there is heterogeneity in the number and type of JEL code assignments between the two groups. Our null hypothesis, therefore, is that authors and editors assign JEL codes to the same papers in the same manner, as opposed to the alternative where they assign them differently:

$$
\begin{aligned}
& H_{o}: \quad J E L_{i, j}=J E L_{i, k} \\
& H_{a}: \quad J E L_{i, j} \neq J E L_{i, k}
\end{aligned}
$$

where $i$ represents a given academic paper, and $j=1, \ldots, n$ and $k=1, \ldots, m$ represent paper-specific JEL codes assigned by the editors and authors respectively, $j \geq 1, k \geq 1$.

\section{Data}

Many articles, when they are first submitted to a journal for publication consideration, contain JEL codes assigned (or suggested) by the author. Later, if those articles are accepted and published, editorial staff assign the official JEL codes which end up in the EBSCO database. From 1990-2008 the American Economic Review (AER) published articles with the usual editorassigned JEL codes, but also with the original author assigned JEL codes remaining visible on the first page of the publication. This availability of dual JEL code assignments - for the same papers - allows us to test whether, and how, editor assigned codes differ from author assigned codes, at least for that two decade time span and in the journal $A E R$.

In this paper we also investigate thematic trends of the top JEL codes currently in use. For this analysis we extend our dataset to a longer time span, 1969-2014, and beyond just the 
$A E R$. For this part of the research we examine JEL code usage in five top general interest journals in the field, including: American Economic Review (AER), Econometrica (E), Journal of Political Economy (JPE), Quarterly Journal of Economics (QJE), and Review of Economic Studies $\left(\right.$ RES). ${ }^{6}$

All article abstracts published in these five journals, for the years 1969-2014, are in the database. The corpus includes abstracts from all research-oriented articles that have been published in English, ${ }^{7}$ including full-length monographs, full-length book reviews, and comments and replies (which do occasionally include an abstract). Entries not included in the dataset include editor's notes, conference announcements and programs, auditor's reports, indexes, and other similar non-research focused entries. As well, entries with no JEL codes listed whatsoever were not included (there were few of these, and generally they were aberrations in the EBSCO database). Special symposium articles are included. ${ }^{8}$ Given these criteria the corpus includes 15,514 articles, some descriptive information for which can be found in Table 1.

The starting year of 1969 was chosen for a specific reason. The JEL classification code system has undergone two significant revisions since its initial implementation at the turn of the twentieth century. ${ }^{9}$ The first major revision was in 1968, the second major revision in 1990 . In order to avoid construction of two different mapping systems to try and harmonize three different JEL code classification schemes, the dataset begins in 1969, thus avoiding any papers that utilized the initial iteration of the JEL code classification scheme. We employ a single mapping

\footnotetext{
${ }^{6}$ This list was chosen after considering a number of different rankings, including Engemann and Wall (2009), Kalaitzidakis et al. (2001), and a variety of online listings. In addition, these journals are the most common ones used in published research that investigates trends in the discipline of economics (Kosnik, 2015; Kosnik, 2014b; Hamermesh, 2013; Card and DellaVigna, 2013; Laband et al., 2002; Laband and Tollison, 2000).

${ }^{7}$ Some of these journals, especially in earlier years, included the occasional article in French or German.

${ }^{8}$ It is worth noting, however, that the American Economic Review's annual Papers and Proceedings issue is not included.

${ }_{9}^{9}$ And as Cherrier (2015) points out, a few less significant revisions as well.
} 
strategy, therefore, to bring the pre-1990 (but post-1968) JEL codes into alignment with the post1990 JEL codes. This mapping strategy relies on that used in Card and DellaVigna (2013), editing it only when a code or category was found to be unrepresented in that scheme. ${ }^{10}$ Appendix A provides the pre-1990 to post-1990 JEL code mapping strategy. As Cherrier (2015) notes, the 1968 revision was about rationalizing multiple classifications that were originally pushed by professionals outside of the discipline who wanted a way to identify categories of expertise for governmental war efforts. ${ }^{11}$ The 1990 revisions were prompted by economists' frustration with the later lack of space, as new approaches in economics developed.

For all of the article abstracts in the dataset we have editor assigned JEL codes, as listed in the EBSCO Information Services database - these are the JEL code assignations you would see if you looked these articles up in EconLit, for example. All of the articles in our dataset have at least one JEL code, 37\% have two JEL codes, 19\% three, 7\% four, 3\% five, a little more than $1 \%$ have six, and a little less than $1 \%$ have as many as seven JEL codes assigned. Seven appears to be the limit for editor assigned JEL codes.

\section{Methodology}

For the comparison of author and editor assigned JEL codes, standard statistical analysis was utilized. For the thematic and spatial network analysis, textual analysis ${ }^{12}$ was employed. Textual analysis is the accumulation of large amounts of textual data, the cleaning and parsing of

\footnotetext{
${ }^{10}$ Note that the Card and DellaVigna (2013) mapping scheme is constructed from information provided in the Journal of Economic Literature (1991), which describes how the pre-1990 JEL codes correspond to the post-1990 codes.

${ }^{11}$ A perusal of the pre-1968 codes is fascinating for the level of minute, and what seems today extremely superfluous, detail.

${ }_{12}$ Textual analysis as a methodological tool has taken off in the last decade in many social science disciplines (most notably political science and psychology), and it has begun to be utilized in the economics literature as well (Kosnik 2015, 2014a, 2014b; Baker et al., 2014; Gentzkow and Shapiro, 2010; Tetlock, 2007; Antweiler and Frank, 2004).
} 
the text with unique algorithms, and then the turning of the text into a database where the words themselves are statistically analyzed for trends and correlative patterns.

The unstructured text of the abstract from each research article was organized within a vector-space model (VSM). In the VSM each element of the vector indicates the occurrence of a word within the document. A collection of documents results in a collection of vectors, and there were 15,514 in this study. Once the raw text from each abstract was input into a relational database, a number of algorithms were performed to clean the data. A typical lemmatization process was then applied in order to reduce the words to their root form, taking note to preserve technical economic terms such as “externality” and "regression.” The text also underwent a standard exclusion process in order to remove words with little semantic value such as pronouns and conjunctions. Finally, in order to make the thematic analysis (discussed below) stable, approximately $10 \%$ of the least frequent words in each of the JEL categories studied were excluded.

The method used to extract thematic topics from the documents (first segmented by JEL category type, C-R) was factor analysis (Rummel, 1970). All words with a factor loading higher than 0.40 were retrieved as part of an extracted topic. ${ }^{13}$ The number of topics returned per analysis was set to ten, and generally ten were returned, but in some instances the algorithm returned fewer than that. The thematic results presented below also include eigenvalues, which indicate the strength, or degree of confidence, in the thematic topics chosen - higher eigenvalues imply greater confidence that the thematic topic described indeed represents a theme in the corpus. Finally, \% cases gives the percentage of articles within each JEL category that is counted as including a particular theme - a higher \% cases implies that the theme is widely

\footnotetext{
${ }^{13}$ Note that topic modeling using factor analysis (as opposed to hierarchical cluster analysis, for example) allows words to be associated with more than one factor. This is often more realistic of the way in which, particularly polysemous words, are used.
} 
represented across the JEL category corpus, while a smaller \% cases implies that the theme (which may be strong, due to a high eigenvalue) is at the same time discussed in a relatively few number of articles overall.

\section{Results - Editor vs. Author Assigned JEL Codes:}

In this first section of results we examine whether there is significant heterogeneity between editor and author assigned JEL codes, as assigned to the exact same papers. Our dataset focuses on $A E R$ articles from 1990-2008, of which there are 1,756. However, while editor assigned JEL codes are provided for every article in the dataset, including reviews and comments, author assigned JEL codes are available only for full-length research articles. Our comparative dataset, therefore, is reduced to 970 articles. Of these, editor assigned JEL codes were different than author assigned JEL codes $43 \%$ of the time - a significant difference.

The fourth and fifth columns of Table 2 show the breakdown of these 970 articles by editor (E) and author (A) assigned JEL category. ${ }^{14}$ In total there are 2489 editor assigned JEL codes for these papers, and 2649 author assigned codes. On average, editors assign 2.57 JEL codes per paper, while authors assign 2.73 codes. A one-tailed t-test finds this difference statistically significant at the $1 \%$ level, though it is a numerically small difference. ${ }^{15}$ Authors are in general more liberal in their use of JEL code assignment than editors. ${ }^{16}$

At the same time, many of these extra author assigned JEL codes appear to differ only by subcategory (for example H00 and H01), and not by broad category (H versus I). When

\footnotetext{
${ }^{14}$ One article can be assigned to more than one JEL code, so the fourth and fifth columns in Table 2 will not sum to 970.

${ }^{15}$ The mean for editor assigned JEL codes, $\mu_{\mathrm{e}}$, is 2.565979 . The mean for author assigned JEL codes, $\mu_{\mathrm{a}}$, is 2.730928. $\boldsymbol{\sigma}_{\boldsymbol{e}}^{2}=1.293069$. $\boldsymbol{\sigma}_{\boldsymbol{a}}^{2}=1.421415$. The t-statistic is 3.118, and the $p$-value is 0.0009 .

${ }^{16}$ Note that editor assigned JEL codes appear to be capped at seven, while authors can assign an unlimited number of codes to a single article.
} 
subcategories are combined so that each article is represented by its broad categories only, there are 1,764 editor assigned codes and 1,582 author assigned codes. The difference is now reversed in favor of editors, as it appears that editors are more liberal in their tendency to assign an article across multiple disciplines. Overall, papers have different JEL code assignments by broad category 52\% of the time. On average, editors assign 1.83 broad JEL codes per paper, while authors assign 1.64 broad JEL codes. A one-tailed t-test finds this difference also statistically significant at the $1 \%$ level, though again the actual numerical difference is small. ${ }^{17,18}$ The black (for "Editor) and gray (for “Author”) frequencies in Figure 1 illustrate this comparison.

Figure 1 tells us a few things. First, there are not any enormous height differences between the "Editor" and "Author" frequencies at any of the category markers, implying roughly similar amounts of category code assignments between authors and editors. However, it is worth noting the "In Common" frequencies, in green, which corresponds to the sixth column in Table 2 (turned into percentages). This shows the total number of articles in each category that received the same JEL code assignment by both editors and authors. This is everywhere less than the code assignments by editors and authors alone. JEL category "P," for example, has 30 articles assigned to it by both editors and authors, but they aren’t the same 30 articles (!); only 20 are in common.

Second, it appears from Figure 1 that authors are more eager to assign their papers to what they likely perceive as the general categories of "C: Mathematical \& Quantitative Methods" and "D: Microeconomics.” Editors, on the other hand, are more discerning when it comes to categories "C" and "D". At the same time, however, editors are more liberal in their

\footnotetext{
${ }^{17}$ The mean for editor assigned broad JEL codes, $\mu_{\mathrm{e}}$, is 1.834021 . The mean for broad author assigned JEL codes, $\mu_{\mathrm{a}}$, is 1.64433. $\boldsymbol{\sigma}_{\boldsymbol{e}}^{2}=0.612657$. $\boldsymbol{\sigma}_{\boldsymbol{a}}^{2}=0.750818$. The t-statistic is 4.203, and the $p$-value is 0.0000 .

${ }^{18}$ While both broad category and total category usage differ by approximately a fifth of a code, note that this difference is more significant for broad category assignments, as less of them are assigned in the first place. In other words, the difference is about $6 \%$ for all categories, but an $11 \%$ usage difference for the broad category codes.
} 
use of nearly all the other categories. In sum, editors seem to be making more of an effort to have articles cross discipline boundaries, while authors don’t cross-list, as much as they fine tune JEL code assignments within a broad category (through their use of numerous subcategory assignments).

This seems to imply, regarding the theoretical motivations described earlier, that editors are more influenced by the motivation to have a JEL code apply as broadly as possible, perhaps in an effort to bring in readers beyond just the most obvious classification categories. Authors, however, are more influenced by the motivation to firmly self-identify their papers into welldefined, specific subject categories, perhaps in order to position themselves to close colleagues in the field. The ultimate actions of authors and editors when assigning JEL code classifications do differ, and in a statistically significant (if numerically small) way.

This result holds for the universe of articles investigated, but are there any differences by subject category? For example, do authors and editors assign codes more similarly in "Q: Agricultural and Natural Resource Economics," as opposed to "D: Microeconomics”? The final column in Table 2 investigates this question, by providing the percentage of articles assigned in common by both authors and editors. All subject categories have differences, but the percent in common ranges from a low of 57.5\% in "C: Mathematical \& Quantitative Methods," to a maximum of $84.3 \%$ in common in "F: International Economics.” The results in this column highlight again the fact that “C: Mathematical \& Quantitative Methods," in particular, appears to be a catch-all category for authors who like to give their papers at least one "quantitative" designation, while editors are more discerning as to what constitutes a truly quantitative paper category designation. This sort of difference/confusion in category interpretation is exactly what 
was behind many of the conflicts in the JEL code classification creation story, as described by Cherrier (2015). ${ }^{19}$

What about over time? The number of observations per year is relatively small (on average, 51 articles per year), however Table 3 does show the number of these articles in each year that have different editor and author assigned JEL codes, and what that percentage is of the overall count of articles. The large (on average 43\%) discrepancy between author and editor assigned JEL codes has stayed relatively consistent over the time span under study, except for the last two years of the dataset, 2007-2008. This appears to be when $A E R$ began a concerted effort to align author and editor assigned JEL codes, which came to complete fruition in $2009 .^{20}$

An interesting final question to ask, is whether these somewhat different JEL code assignments between editors and authors imply any thematic differences as well. Are specific topics or policy applications filed differently by authors and editors across the subject categories? This would be particularly important for employers, government agencies, journalists, or others outside the field who may search economics research by JEL code, seeking specific topical information. We will return to this question after we introduce thematic trends in the JEL code categories more broadly in the next section.

\section{Results - Overall Thematic Analyses:}

Table 2 provides the 16 JEL categories studied, including (in the third column) the number of articles represented from all five journals studied, from 1969-2014, and thus the observations included in the thematic/spatial network analysis. The total number of articles adds

\footnotetext{
${ }^{19}$ Indeed, besides the broad versus tailored debate about how detailed to create JEL categories, there were debates about whether to create additional categories that distinguished theory, methodologies, and applied work. It may be that authors assume methodology is divided up into category " $\mathrm{C}$," and that is why they use it so much, as opposed to editors who see it is as but another category of overall research.

${ }^{20} 2009$ marks the first year that author and editor assigned JEL codes are always and for every paper identical.
} 
to more than 15,514 because articles listed with more than one JEL code are represented more than once. Some categories, for example “K: Law and Economics,” and "M: Business Administration \& Business Economics; Marketing; Accounting” had relatively few articles, while others, like “D: Microeconomics” and “E: Macroeconomics” had many; the categories with more articles were often able to return a greater number of themes than the categories with fewer articles and a smaller word base. It is worth reiterating that the thematic analyses uncovered here represent themes from these JEL categories as published just in the top general interest journals studied, and not across the entire economics literature. Categories with prolific field journals, for example, may certainly have had other or additional topics represented over this time period; what is presented here are the main topics discussed in the top general interest journals in economics.

Tables 4-19 display the thematic results for each of the 16 JEL categories studied. This is an analysis of all the research article abstracts that include that JEL category, ${ }^{21}$ for the entire length of the study (from 1969-2014). The first column in each table, Theme, describes the themes for each research category ${ }^{22}$, the second column, Keywords, lists the keywords that the algorithm identified as composing those themes, and the last two columns present the eigenvalues and the percentage of cases that include that theme. A few observations are immediately apparent.

\footnotetext{
${ }^{21}$ Most of the research articles (83\%) have more than one JEL code, and so are categorized in more than one JEL corpus; at the same time, if an article has the same JEL code twice (for example H0O and H01), it is utilized just once in the given JEL code ("H") corpus.

${ }^{22}$ The exact label (e.g. "Game Theory”) was assigned by the author after a perusal of both the keywords utilized and the corresponding articles assigned to that theme.
} 
First, there are a number of themes that cross JEL categories and appear repeatedly throughout the corpus. ${ }^{23}$ "Labor \& Employment" is the most prevalent theme, appearing in seven of the eighteen categories. "Voting \& Elections," “Gender Issues,” "Risk Aversion,” “Auctions,” “Estimation Techniques,” and “Game Theory” are also relatively prevalent. This illustrates that there are some topics which dominate the research interests of economists, across disciplines.

A second observation is that, while there are some themes that are common across many categories, at the same time, there are a few JEL categories which are extremely distinctive and share very few, if any, top themes with any of the other categories. There are three of these distinctive categories and they are "I: Health, Education, and Welfare,” "M: Business Administration \& Business Economics, Marketing, Accounting,” and “Q: Agricultural \& Natural Resource Economics, Environmental \& Ecological Economics.” The top themes in these categories are often applied and include things like "Donor Exchanges,” "Newborns,” “Advertising,” “Entrepreneurship,” “Sulfur Emissions,” and “Forestry Resources.”

Overall, the top themes in each category accord with what one would expect for each JEL code, including macroeconomic categories (i.e. “E” "F” “G”) containing monetary policy as a top theme, and things like "Public Goods” being a top theme in "H: Public Economics," and “Racial Demographics” being a top theme in “J: Labor and Demographic Economics.” The results appear to confirm that categorization of research articles by JEL category code conform to expectations and are meaningful. This is reassuring, especially given the contentious, and at times confusing, tug-of-war that went into the creation of the JEL code classification system (Cherrier, 2015).

\footnotetext{
${ }^{23}$ Note that these common themes are often supported by somewhat different keywords in different JEL category analyses. This implies that the particular foci of research questions studied across JEL categories may have differed, while the broader category of, say, "Game Theory” more generally applied.
} 
Returning to the dataset of just $A E R$ articles from 1990-2008, we investigate the top themes as described by the author-assigned articles versus the editor-assigned articles. Specific results are available from the author upon request, but on average only about half of the top thematic categories for each JEL category were shared between editor assigned and author assigned papers. This is not actually surprising. As the "In Common" frequencies in Figure 1 indicates, quite a number of articles were not similarly assigned by editors and by authors, therefore, it is not all that surprising that a textual analysis of their top themes differs as well. What this implies for outsiders exploring academic research, however, is that authors and editors may view papers rather differently and that they should explore broadly and widely to discover thematic topics that may be very specific.

\section{Thematic Analyses Over Time:}

Next, for the JEL categories that contain enough research articles for stable decennial analysis, we explore how top themes may have changed over time. We divide 1969-2014 into four distinct time periods: I: 1969-1979, II: 1980-1989, III: 1990-1999, and IV: 2000-2014, and run the same thematic algorithm described in the methodology section above, but for each period. This analysis yielded several interesting results.

For category “C: Mathematical \& Quantitative Methods,” one discovery is that "InputOutput Models” were a top theme in period I, but at no other time. In addition, applied themes were nowhere to be found in this category except for in the very last period, IV, where "Gender Issues” suddenly showed up as a top research theme.

For category "D: Microeconomics," the main interesting result was that the top themes changed substantially in nearly every period I through IV. Microeconomic papers can have very 
applied contexts, and this shows, with topics like "Stocks” “Taxes” "College \& Students” and "Traffic" showing up as top themes in the early years, and completely different topics, including “Gender Issues” “The Firm” "Contracts” and “Auctions,” showing up in periods III and IV. The JEL category "D: Microeconomics” appears to have a lot going on within it!

For category "E: Macroeconomics," the topics were relatively similar across periods. "Risk" appeared as a top theme across the decades, however, when digging deeper and investigating what types of research papers composed this topic, the type of risk studied did seem to change. In period I "Risk" was mostly about portfolio risk, while in time periods II-IV the theme of "Risk" morphed more into risk aversion and utility effects. "Borrowing," including private sector, life-cycle, and government borrowing, appears to have been an extremely strong theme in period III, but not in any of the other time periods. Finally, it may be noteworthy that only in period IV do we get a top theme labeled "Disasters" which includes such keywords as rare, disaster, risk-free, premium, equity, and Barro.

For most of the other categories that were able to be broken down by time period, ${ }^{24} \mathrm{a}$ main result across the JEL category codes appears to be that the top themes became more and more applied as time went on. Particularly in period IV we start to see themes that are less theoretical or estimation oriented, such as "mathematical techniques" and "models of utility," and more about particular contexts including, "Health Care" "Cars” "IPOs” "Oil” and “Immigration.”

\footnotetext{
${ }^{24}$ Specific results per JEL category available from the author upon request.
} 


\section{Spatial Network Analysis:}

Finally, we can investigate with spatial network analysis the relationships between different JEL categories and themes, to try and elucidate and investigate areas of economics research that do, or do not, seem to occur (or at least, be categorized) together.

To begin, Figure 2 presents a network analysis of the sixteen JEL codes over the entire timespan of the dataset, 1969-2014. The graph was created with the open source platform Gephi, ${ }^{25}$ and the layout derives from a Force Atlas algorithm (Jacomy et al., 2014). The nodes are the 16 JEL category codes analyzed throughout this paper, the edges are created by a count of the number of times any two JEL codes appear together in a paper in the dataset (as assigned by editors), and a modularity process was created to distinguish two communities: relatively strongly related categories (green, and with thicker edges) and relatively weaker connections (red, and with thinner edges). Approximately $2 / 3$ of the connections are categorized as strong, 1/3 as weak. Figure 2 gives you a sense of the relationships of the JEL codes between each other. Categories "C," "D," and "E" are some of the strongest and most central, while many of the alphabetically later categories (i.e. "M” through "R”) are weakly related and do not appear to be centrally categorized areas of research. Similar network analyses for the time periods I through IV reveal remarkably similar graphs.

Table 20 further elucidates the network analysis by providing information on the percentages of the 15,514 articles, as assigned by editors, that have JEL codes listed in more than one category. Again one can see the centrality and prevalence of categories C, D, and E to the network, and the relative isolation of the later categories, including $\mathrm{K}, \mathrm{M}, \mathrm{N}, \mathrm{P}, \mathrm{Q}$, and $\mathrm{R}^{26}$

\footnotetext{
${ }^{25}$ Gephi can be downloaded at: http://gephi.github.io/

${ }^{26}$ Information on overlaps at a finer level of detail (i.e. 2-character, C0, and 3-character, C00 overlaps) can be made available by the author upon request.
} 
In an effort to reveal spatial relationships between themes, and not just JEL categories, we also performed a network analysis of the 91 themes described in Tables 4-19. Figure 3 presents that spatial relationship for the time period 1969-2014. ${ }^{27}$ Due to the fact that there are 91 nodes, and subsequently, 4,186 undirected edges, the graph is too dense to label everything with clarity, so instead just the thematic "outliers" are labeled in an effort to illustrate the less connected themes. ${ }^{28}$ One thing of interest to note is that many of the outlier topics are listed as top themes in JEL category “M: Business Administration \& Business Economics," which in Figure 2 is also an outlier as a JEL category. Business Economics as a category appears to be somewhat set apart from the rest of the research discussion in the wider field of economics, even more so than some of the other outlier fields from Figure 2 (i.e. JEL categories N-R).

Similar network analyses for the time periods I through IV reveal graphs with many of the same outliers. ${ }^{29}$ The exact shapes of the network analyses change somewhat in each decade, but a majority of the nodes portrayed as outliers (including "Firm Takeovers," "Retail Sales," “Entrepreneurship,” and “Bait and Switch and Seller Disclosures”) remain the same. In other words, the relationships between the categories C-R has remained relatively consistent over time.

\section{Conclusions}

A main result from this research is that there is indeed a statistically significant disparity in use of JEL code assignments between editors and authors, for the same papers. This

\footnotetext{
${ }^{27}$ This graph was also created with Gephi and utilizes a Force Atlas algorithm.

${ }^{28}$ The reasons for the "outlier" statuses are not clear. It could be that these topics are simply tangential to much of the rest of the research discussion in the field, or, it could be that these topics are up and coming and will become more integrated in the future. There are many possible reasons these themes are located to the edges of the network analysis, a further investigation into such reasons would be a useful area for future research.

${ }^{29}$ This is unsurprising as the 91 themes analyzed are the same in every time period I through IV. If instead different network analyses were performed, limited to the top themes from each particular decade only, then the relevant graphs and outliers would likely be different. When analyzing all 91 themes over time, however, the change in relative emphasis over the decades appears small.
} 
surprising result is tempered by the fact that while the statistical significance is strong, the actual size effect is small, with often just one or two different JEL codes per paper. Specifically, these quantitative results uncover the surprising fact that authors tend to apply more total JEL codes to their papers (though they are distinguished often by differing subcategories and not by broad category), while editors assign less total JEL codes per paper, but more codes to a given paper that cross discipline boundaries. Perhaps editors (and their staff) are making an effort to market the articles they publish across a wider audience? Debates as to whether JEL codes should be broadly interpreted or narrowly defined, as well as whether new methodological categories of JEL codes should be created appears to be ongoing. Future research into the motivations for this result would be worthwhile. It would also be helpful to understand this result before any further iterations to the JEL code classification scheme are considered in the future.

The second result from this research survey is a more comforting one; that JEL category codes do appear to represent papers that study topics and themes one would expect to be assigned to those codes. Natural resource economics (“Q”), for example, includes papers analyzing sulfur emissions and forestry resources, and labor economics (“J”) includes papers analyzing labor, employment, education, and racial demographics. Had this been different, that would have been surprising indeed.

A third result from this research is that over the long time span from 1969-2014, across all JEL category codes, a common trend has been the move to more applied topics and papers and away from primarily theoretical papers. As the top themes suggest, the discipline of economics is moving towards a more applied, public policy focused direction.

Finally, spatial network analysis has given us a glimpse into which thematic topics appear to be relative outliers in the broader research discussion in economics, and which are more 
integral. While many of the later JEL categories (i.e. "M" through “R”) are spatially further away, “M: Business Administration \& Business Economics” wins for having the most top themes the furthest away from other topics studied in the field. It is as if business economics really is housed in a college separate from the rest of the economics school. 
Table 1 - Article Counts, per Journal and Over Time

\begin{tabular}{|l|c|c|c|c|c|c|c|}
\hline \multicolumn{1}{|c|}{ Journal } & $\mathbf{1 9 6 9}$ & $\mathbf{1 9 7 0 s}$ & $\mathbf{1 9 8 0 s}$ & $\mathbf{1 9 9 0 s}$ & $\mathbf{2 0 0 0 s}$ & 2010s & Totals \\
\hline American Economic Review & 122 & 1,168 & 1,193 & 866 & 988 & 626 & 4,963 \\
\hline Econometrica & 63 & 967 & 839 & 544 & 605 & 319 & 3,337 \\
\hline Journal of Political Economy & 77 & 975 & 675 & 521 & 425 & 154 & 2,827 \\
\hline Quarterly Journal of Economics & 50 & 534 & 564 & 448 & 413 & 211 & 2,220 \\
\hline Review of Economic Studies & 45 & 518 & 524 & 394 & 430 & 256 & 2,167 \\
\hline Totals & 357 & 4,162 & 3,795 & 2,773 & 2,861 & 1,566 & 15,514 \\
\hline
\end{tabular}


Table 2 - JEL Subjects

\begin{tabular}{|c|c|c|c|c|c|c|}
\hline $\begin{array}{c}\text { JEL } \\
\text { Subject } \\
\text { Code }\end{array}$ & Subject & $\begin{array}{c}\text { Total } \\
\text { Number } \\
\text { of } \\
\text { Articles }\end{array}$ & $\begin{array}{c}\text { E } \\
\text { AER } \\
\text { Articles }\end{array}$ & $\begin{array}{c}\text { A } \\
\text { AER } \\
\text { Articles }\end{array}$ & $\begin{array}{c}\text { E\&A AER } \\
\text { Articles in } \\
\text { Common }\end{array}$ & $\begin{array}{l}\text { E\&A AER } \\
\text { Articles in } \\
\text { Common } \\
\text { Percentage }\end{array}$ \\
\hline $\mathrm{C}$ & Mathematical \& Quantitative Methods & 3902 & 86 & 133 & 63 & 57.5 \\
\hline $\mathrm{D}$ & Microeconomics & 4766 & 359 & 362 & 280 & 77.7 \\
\hline $\mathrm{E}$ & Macroeconomics \& Monetary Economics & 3723 & 216 & 193 & 153 & 74.8 \\
\hline F & International Economics & 1614 & 136 & 125 & 110 & 84.3 \\
\hline $\mathrm{G}$ & Financial Economics & 1394 & 133 & 107 & 98 & 81.7 \\
\hline $\mathrm{H}$ & Public Economics & 1475 & 84 & 82 & 55 & 66.3 \\
\hline $\mathrm{I}$ & Health, Education, and Welfare & 638 & 62 & 44 & 38 & 71.7 \\
\hline $\mathrm{J}$ & Labor and Demographic Economics & 2648 & 164 & 124 & 104 & 72.2 \\
\hline $\mathrm{K}$ & Law and Economics & 240 & 26 & 35 & 22 & 72.1 \\
\hline $\mathrm{L}$ & Industrial Organization & 1757 & 163 & 117 & 89 & 63.6 \\
\hline $\mathrm{M}$ & Business Administration \& Business Economics; Marketing; Accounting & 263 & 36 & 21 & 17 & 59.6 \\
\hline $\mathrm{N}$ & Economic History & 318 & 45 & 36 & 26 & 64.2 \\
\hline $\mathrm{O}$ & Economic Development, Technological Change, \& Growth & 1056 & 158 & 110 & 92 & 68.7 \\
\hline $\mathrm{P}$ & Economic Systems & 362 & 30 & 30 & 20 & 66.7 \\
\hline Q & $\begin{array}{l}\text { Agricultural \& Natural Resource Economics; Environmental \& } \\
\text { Ecological Economics }\end{array}$ & 576 & 31 & 19 & 18 & 72 \\
\hline $\mathrm{R}$ & Regional, Real Estate, and Transportation Economics & 486 & 28 & 24 & 19 & 73.1 \\
\hline
\end{tabular}

* Percentage calculated by taking the average of "E AER Articles" and “A AER Articles" and dividing it into "E\&A AER Articles in Common" 
Figure 1 - Editor vs. Author Assigned JEL Codes

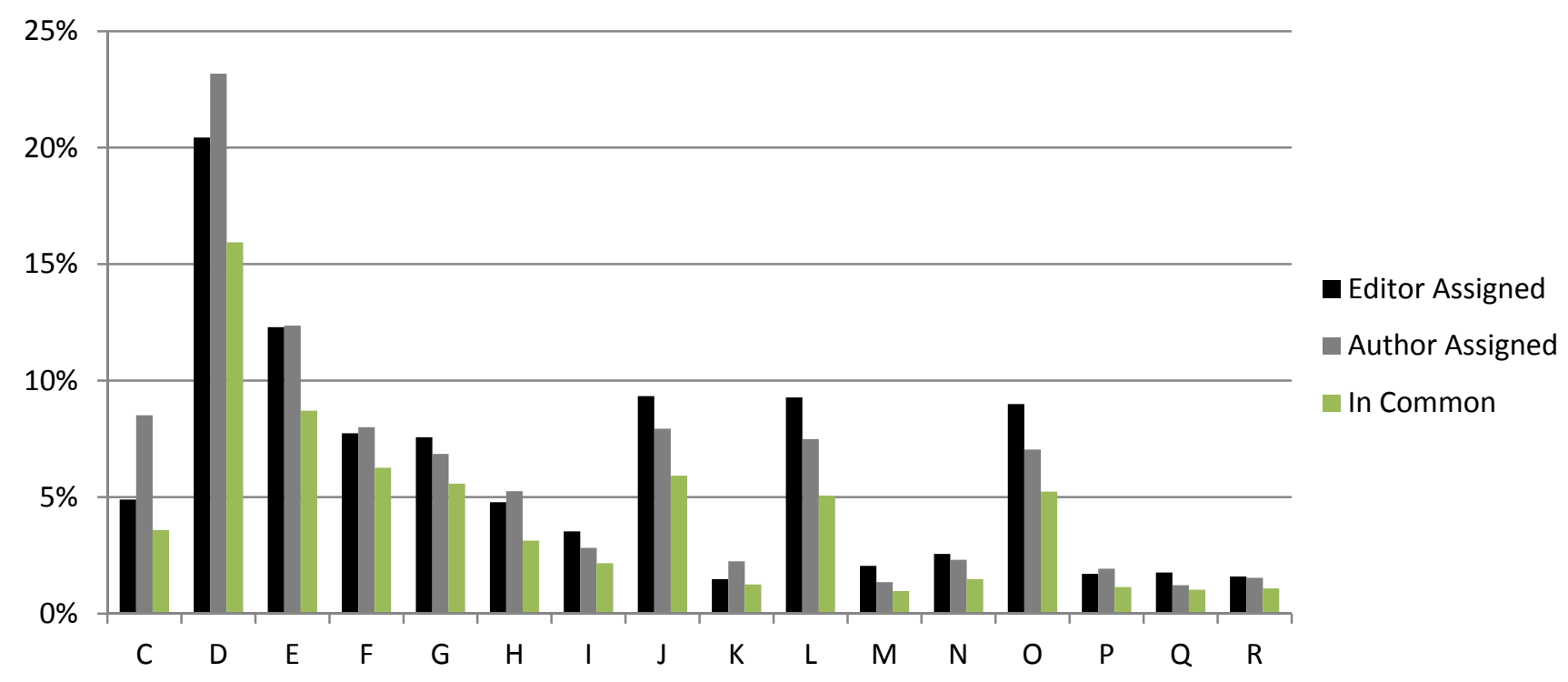


Table 3 - Author and Editor Distinctions Over Time

\begin{tabular}{|c|c|c|}
\hline Year & $\begin{array}{c}\text { \# Articles with } \\
\text { Different JEL Code } \\
\text { Assignments }\end{array}$ & $\begin{array}{c}\text { \% Articles with } \\
\text { Different JEL Code } \\
\text { Assignments }\end{array}$ \\
\hline 2008 & 8 & 13.56 \\
\hline 2007 & 1 & 1.96 \\
\hline 2006 & 17 & 30.91 \\
\hline 2005 & 28 & 50.00 \\
\hline 2004 & 31 & 53.45 \\
\hline 2003 & 27 & 50.94 \\
\hline 2002 & 28 & 58.33 \\
\hline 2001 & 23 & 43.40 \\
\hline 2000 & 20 & 43.48 \\
\hline 1999 & 28 & 63.64 \\
\hline 1998 & 27 & 57.45 \\
\hline 1997 & 21 & 48.84 \\
\hline 1996 & 26 & 50.98 \\
\hline 1995 & 19 & 35.19 \\
\hline 1994 & 31 & 57.41 \\
\hline 1993 & 21 & 39.62 \\
\hline 1992 & 13 & 24.07 \\
\hline 1991 & 27 & 50.94 \\
\hline 1990 & 14 & 36.84 \\
\hline
\end{tabular}


Table 4 - Thematic Analysis JEL Category “C”

\begin{tabular}{|c|c|c|c|c|}
\hline & Theme & Keywords & Eigenvalue & \% Cases \\
\hline 1 & $\begin{array}{l}\text { Estimation } \\
\text { Techniques }\end{array}$ & identification; estimation; nonparametric & 11.28 & 11.05 \\
\hline 2 & Price Theory & demand; labor; wage; supply; price & 4.88 & 21.60 \\
\hline 3 & Game Theory & $\begin{array}{l}\text { game; player; payoff; strategy; repeat; equilibrium; nash; equilibria; } \\
\text { play; action }\end{array}$ & 3.64 & 27.81 \\
\hline 4 & Hypothesis Testing & $\begin{array}{l}\text { null; test; hypothesis; testing; wald; statistics; ratio; statistic; } \\
\text { multiplier }\end{array}$ & 3.3 & 15.76 \\
\hline 5 & Equilibrium & economy; exchange; allocation; competitive; equilibrium & 2.77 & 24.50 \\
\hline 6 & Auctions & seller; buyer; bid; offer; auction & 2.71 & 6.56 \\
\hline 7 & OLS & square; least; variable; estimator; equation; regression; coefficient & 2.65 & 25.55 \\
\hline 8 & $\begin{array}{l}\text { Expected Utility \& } \\
\text { Risk Aversion }\end{array}$ & risk; utility; aversion; expect & 2.57 & 14.45 \\
\hline 9 & Time Series & cointegration; root; series; time; unit & 2.44 & 16.20 \\
\hline 10 & Monte Carlo & carlo; monte; sample & 2.38 & 8.18 \\
\hline
\end{tabular}

Table 5 - Thematic Analysis JEL Category "D”

\begin{tabular}{|c|c|c|c|c|}
\hline & Theme & Keywords & Eigenvalue & $\%$ Cases \\
\hline 1 & Bequests & bequest; child & 6.16 & 2.06 \\
\hline 2 & Auctions & auction; bid; bidder; seller; buyer & 2.94 & 6.74 \\
\hline 3 & Voting \& Elections & voter; election; vote; electoral; candidate; political & 2.73 & 9.27 \\
\hline 4 & Game Theory & game; player; payoff & 2.57 & 9.23 \\
\hline 5 & Risk Aversion & risk; aversion; risky & 2.47 & 8.02 \\
\hline 6 & $\begin{array}{l}\text { Labor \& } \\
\text { Employment }\end{array}$ & worker; wage; labor; job; employer; unemployment; employment & 2.39 & 9.27 \\
\hline 7 & $\begin{array}{l}\text { Moral Hazard \& } \\
\text { Adverse Selection }\end{array}$ & hazard; moral; adverse; contract; selection & 2.27 & 9.44 \\
\hline 8 & $\begin{array}{l}\text { Household } \\
\text { Consumption }\end{array}$ & data; estimate; household; consumption; test; expenditure & 2.2 & 28.07 \\
\hline
\end{tabular}

\section{Table 6 - Thematic Analysis JEL Category "E”}

\begin{tabular}{|c|c|c|c|c|}
\hline & Theme & Keywords & Eigenvalue & \% Cases \\
\hline 1 & Monetary Policy & rate; monetary; nominal; inflation; interest; real; money & 6.79 & 38.25 \\
\hline 2 & Competition \& Firms & firm; competition; competitive; monopoly & 2.8 & 19.29 \\
\hline 3 & $\begin{array}{l}\text { Labor \& } \\
\text { Employment }\end{array}$ & worker; job; unemployment; wage; labor; employment; employer & 2.67 & 17.35 \\
\hline 4 & Taxation & income; consumption; tax; wealth; propensity & 2.62 & 18.43 \\
\hline 5 & Hypothesis Testing & estimate; hypothesis; test & 2.42 & 15.85 \\
\hline 6 & $\begin{array}{l}\text { International } \\
\text { Economy }\end{array}$ & country; foreign; world & 2.35 & 10.42 \\
\hline 7 & Production Functions & production; input; substitution; factor; function & 2.34 & 23.72 \\
\hline 8 & Business Cycle & business; cycle; fluctuation; procyclical & 2.2 & 10.23 \\
\hline 9 & Risk Aversion & risk; aversion & 2.12 & 4.51 \\
\hline 10 & Federal Reserve & bank; reserve; federal & 2.06 & 4.43 \\
\hline
\end{tabular}


Table 7 - Thematic Analysis JEL Category "F"

\begin{tabular}{|c|c|c|c|c|}
\hline & Theme & Keywords & Eigenvalue & \% Cases \\
\hline 1 & Exports & exporter; destination; export; firm & 13.09 & 15.68 \\
\hline 2 & Growth Factors & growth; technical; capital; steady; function & 4.02 & 26.21 \\
\hline 3 & Monetary Policy & monetary; exchange; balance; rate & 3.91 & 32.03 \\
\hline 4 & $\begin{array}{l}\text { Factor Endowments } \\
\text { \& Trade }\end{array}$ & factor; endowment; comparative; theorem; heckscher-ohlin & 3.31 & 15.86 \\
\hline 5 & Tariffs & tariff; import & 3.23 & 14.62 \\
\hline 6 & Sovereign Debt & debt; default; sovereign; lending; borrowing & 2.95 & 5.27 \\
\hline 7 & Exchange Rates & parity; exchange; spot & 2.89 & 15.49 \\
\hline 8 & $\begin{array}{l}\text { International } \\
\text { Investment }\end{array}$ & $\begin{array}{l}\text { multinational; foreign; subsidiary; fdi; investment; direct; } \\
\text { multinationals }\end{array}$ & 2.77 & 21.31 \\
\hline & $\begin{array}{l}\text { International Trade } \\
\text { Agreements }\end{array}$ & multilateral; negotiation; agreement; wto; organization; member & 2.69 & 5.33 \\
\hline
\end{tabular}

Table 8 - Thematic Analysis JEL Category “G”

Theme

1 Lending

2 Risk Aversion

3 Firm Takeovers Estimation

4 Techniques

5 Trade

6 Health Insurance Labor \&

7 Employment

8 Taxation

9 Monetary Policy

10 Investment Returns
Keywords borrower; loan; lender; lending; credit; bank utility; aversion takeover; shareholder; tender asymptotic; procedure; estimation; estimator trading; trader; price; rational health; insurance; insurer; employee; coverage; plan employment retain; tax; taxation; corporate; personal nominal; monetary; interst; rate; real premium; return

Eigenvalue \% Cases

\begin{tabular}{|c|c|c|}
\hline & 12.53 & 15.42 \\
\hline 3.8 & 7.89 \\
\hline & 3.37 & 3.44 \\
\hline & 3.25 & 4.81 \\
\hline 2.99 & 31.35 \\
\hline 2.87 & 8.11 \\
\hline & 2.81 & 1.22 \\
\hline & 2.69 & 9.25 \\
\hline & 2.6 & 27.98 \\
\hline
\end{tabular}

Table 9 - Thematic Analysis JEL Category "H"

Theme

1 Public Goods

2 Education

3 Retirement

4 Auctions

5 Income Taxation Rebates \& Transitory

6

Income

Domestic \& Foreign

7 Market Instruments

8 Corporate Taxation Labor \&

9 Employment
Keywords public; goods school; student; score; achievement; parent; district; teacher; peer; causal; college security; social; annuity; generation; bequest; retirement auction; bidder; bid; procurement; highway; contract mirrlees; optimal; utility rebate; permanent; transitory domestic; import; foreign capital; corporate; tax; rate labor; supply, hour
Eigenvalue \% Cases

\begin{tabular}{|c|c|c|}
\hline 13.08 & 22.17 \\
\hline & 4.16 & 6.51 \\
\hline 3.72 & 14.24 \\
\hline 3.45 & 3.32 \\
\hline 3.33 & 15.46 \\
\hline & & \\
& & \\
& & \\
& & \\
& & \\
& & \\
& & \\
& & 42.98 \\
\hline & & \\
& & \\
\hline
\end{tabular}


Table 10 - Thematic Analysis JEL Category "I"

Theme

Keywords

Eigenvalue \% Cases

Health Insurance

Estimation

2 Techniques

3 Education

4 Donor Exchanges

5 China

6 Newborns

33.86

regressor; liml; estimator; coefficient; square; statistics score; student; school; achievement donor; transplant; kidney; donation; exchange; priority china; sex; female; girl; ratio newborns; gram; threshold; discontinuity; side; diagnostic

\begin{tabular}{|c|c|c|}
\hline & 33.86 & 10.82 \\
& & \\
& 6.05 & 3.45 \\
\hline & 5.77 & 27.43 \\
\hline & 5.48 & 1.57 \\
\hline & 5.35 & 5.64 \\
\hline
\end{tabular}

\section{Table 11 - Thematic Analysis JEL Category “J”}

\begin{tabular}{|c|c|c|c|}
\hline Theme & Keywords & Eigenvalue & \% Cases \\
\hline Racial Demographics & black; urban; white & 7.77 & 5.66 \\
\hline Education & school; student; college; score; attend & 3.1 & 7.78 \\
\hline Gender Issues & woman; female; marry; man; marriage & 2.96 & 11.52 \\
\hline $\begin{array}{l}\text { Labor \& } \\
\text { Employment }\end{array}$ & worker; job; firm; search; labor & 2.75 & 47.81 \\
\hline Human Capital & human; capital; investment; accumulation & 2.62 & 14.39 \\
\hline Retirement & security; retirement; pension; life; social & 2.56 & 12.39 \\
\hline $\begin{array}{l}\text { Estimation } \\
\text { Techniques }\end{array}$ & estimate; estimation; estimator & 2.49 & 22.09 \\
\hline Unions & bargaining; union; collective; strike; dispute & 2.42 & 7.36 \\
\hline Children \& Family & child; parent; family; fertility; mother & 2.31 & 12.42 \\
\hline Unemployment & unemployment; duration; spell & 2.24 & 11.52 \\
\hline
\end{tabular}

\section{Table 12 - Thematic Analysis JEL Category “K”}

Theme

1 Law Enforcement

Estimation

2 Techniques

3 Incarceration

4 Voting \& Elections

5 Energy Regulation

6 Racism

7 Game Theory

8 Bankruptcy

9 Internet

10 Mergers \& The Firm
Keywords

violation; origin

lasso; iv; post-lasso; estimator; validity; modification; conditional; sample; selection; deal; widely; perform; endogenous; rely; imperfect release; prison; prisoner; offender; inmate; recidivism; month; certainty; parole intolerant; citizen; majority; voter; emerge; society; potentially; mistake; end; seek; auditing; punish; improve; enforce; vote diesel; fuel; substitute; elasticity; tax; fall; respect; program; fraction; regulatory; similar; federal race; racial; defendant; jury; trial; white; percentage; black communication; player; signal; shock; cut; fact; receive; cooperation; end; imperfect; repeat; long; subject scale; bankruptcy; file; avoid; entry; damage; asset; hazard internet; sex; access; consumption; victim; finding surplus; antitrust; consumer; merger; authority; commitment; competition
Eigenvalue \% Cases

\begin{tabular}{|c|c|}
\hline 33.53 & 4.17 \\
\hline 9.79 & 14.58 \\
\hline 7.34 & 8.75 \\
\hline 6.63 & 17.5 \\
\hline 6.14 & 14.17 \\
\hline 6.05 & 8.75 \\
\hline 5.84 & 16.67 \\
\hline 5.69 & 7.50 \\
\hline 5.41 & 10.00 \\
\hline 5.37 & 9.17 \\
\hline
\end{tabular}


Table 13 - Thematic Analysis JEL Category "L"

Theme

5

6

7

8

9 Employment

Contracts

Regulation

Trade

Auctions

Labor \&
Keywords

retail; retailer

Transportation

Firm Integration

Environmental

Voting \& Elections

contract

regulator congestion; traffic; road; highway; airport; airline

downstream; upstream; vertical; integration

regulation; environmental; regulate; regulatory; air; pollution;

trade; export; domestic; foreign; country; international; exporter

medium; vote; news; television; newspaper; political

bid; auction; bidder; lease

labor
Eigenvalue \% Cases

\begin{tabular}{|c|c|}
\hline 8.83 & 3.02 \\
\hline 2.89 & 2.68 \\
2.78 & 8.99 \\
\hline 2.73 & 3.81 \\
\hline & \\
2.53 & 7.34 \\
\hline 2.48 & 12.69 \\
\hline 2.44 & 3.93 \\
\hline & 3.13 \\
\hline & 6.66 \\
\hline
\end{tabular}

Table 14 - Thematic Analysis JEL Category “M”

Theme

1 Workplace

2 Advertising

Structural Decision-

3 Making

4 Suppliers

5 Seniority \& Status

Bait \& Switch \&

6 Seller Disclosures

7 Taxation

8 Entrepreneurship
Keywords

personnel; workplace; friend; social; externality; works; piece

contest; participant; win; attract; attention; nonpecuniary; restrict; existence; random; averse; advertisement; lack; enter; participation; frequently

Hierarchy; decentralize; decision-making; organizational; division; coordinate; dominate; authority; strategically; centralize; coordination; maker; dissent; credibility seller status; prior; award; unite

disclosure; sender; receiver; switch; bait taxable; responsiveness; exercise; elasticity; rich; salary; short-run; respect; tax; timing; zero entrepreneur
Eigenvalue \% Cases

\begin{tabular}{|c|c|}
\hline 38.69 & 6.84 \\
7.27 & 15.97 \\
\hline & \\
7.08 & 10.27 \\
\hline 6.71 & 4.94 \\
\hline 6.63 & 3.80 \\
\hline 6.29 & 2.28 \\
\hline 6.24 & 10.65 \\
\hline 6.02 & 3.04 \\
\hline
\end{tabular}

\section{Table 15 - Thematic Analysis JEL Category “N”}

\begin{tabular}{|c|c|c|c|c|}
\hline & Theme & Keywords & Eigenvalue & \% Cases \\
\hline 1 & Gender Issues & $\begin{array}{l}\text { young; gi; bill; korean; veteran; college; man; female; attainment; } \\
\text { sharp }\end{array}$ & 41.76 & 10.69 \\
\hline 2 & GDP \& Fertility & $\begin{array}{l}\text { unprecedented; expectancy; figure; acquire; widespread; virtually; } \\
\text { elite; gdp; fertility; illustrate; sustain; vast; traditional; } \\
\text { simultaneously; majority }\end{array}$ & 8.35 & 11.64 \\
\hline 3 & Colonialism & $\begin{array}{l}\text { import; interwar; stagnation; nation; asia; material; metropolitan; } \\
\text { foreign; responsible; fuel; effort; japanese; farm; assume; colonial }\end{array}$ & 7.83 & 12.89 \\
\hline 4 & Progress \& Growth & $\begin{array}{l}\text { smith; remarkable; attention; james; progress; cite; considerable; } \\
\text { famous }\end{array}$ & 7.19 & 6.92 \\
\hline 5 & Voting \& Elections & $\begin{array}{l}\text { voter; electoral; politician; vote; election; party; implement; radio; } \\
\text { competition; decide; turnout; convergence; focus }\end{array}$ & 6.99 & 11.32 \\
\hline 6 & $\begin{array}{l}\text { Underdeveloped } \\
\text { Countries }\end{array}$ & $\begin{array}{l}\text { life; brazil; conjecture; ldc; analytical; correspond; product; } \\
\text { persistent; sample }\end{array}$ & 6.96 & 7.23 \\
\hline 7 & Monopoly Power & monopoly; conduct; company & 6.60 & 4.40 \\
\hline
\end{tabular}


Table 16 - Thematic Analysis JEL Category “O”

Theme

1 Education

Progress \& Growth

Lending

4 Innovation

5 Voting \& Elections

Labor \&

6 Employment

7 Gender Issues

8 Insurance
Keywords

randomize; school; score; deviation; experiment; child

harrod; hick; sato; neutral; neutrality; progress; david; technical;

function

default; borrower; lender; repayment; loan

imitation; schumpeter; innovative; perfect; innovation; monopoly

electoral; election; political; politician; voter

skill-biased; skill; skilled; wage; worker; unskilled; premium marriage; woman; man; female; sex

hazard; moral; insurance
Eigenvalue \% Cases

\begin{tabular}{l|l}
18.86 & 9.09
\end{tabular}

4.7

4.23

4.12

\begin{tabular}{l|r}
4.12 & 14.96 \\
\hline 3.49 & 5.02 \\
\hline
\end{tabular}

3.36

3.34

3.18

Table 17 - Thematic Analysis JEL Category “P”

\begin{tabular}{|c|c|c|c|c|}
\hline & Theme & Keywords & Eigenvalue & \% Cases \\
\hline 1 & $\begin{array}{l}\text { Decentralized } \\
\text { Planning Procedures }\end{array}$ & $\begin{array}{l}\text { hurwicz; lange; malinvaud; arrow; iterative; scale; decentralize; } \\
\text { mixture; command; category; procedure; partially; applicable; } \\
\text { resemble; clear }\end{array}$ & 10.15 & 13.54 \\
\hline 2 & Rationing Goods & $\begin{array}{l}\text { anticipate; inventory; priority; error; operating; thing; shortage; } \\
\text { practice; occur; meet; soviet-type; norm; ration; highly; post }\end{array}$ & 9.3 & 11.05 \\
\hline 3 & National Trade & $\begin{array}{l}\text { non-economic; throughout; constrain; implicit; variety; strategic; } \\
\text { export; constitute; national; opportunity; specific; import; } \\
\text { distinguish; entail; turn }\end{array}$ & 8.93 & 10.22 \\
\hline 4 & $\begin{array}{l}\text { Optimal Growth \& } \\
\text { Dynamics }\end{array}$ & $\begin{array}{l}\text { stationary; stochastic; gale; generalization; infinite; optimality; } \\
\text { optimal }\end{array}$ & 8.57 & 16.02 \\
\hline 5 & Gender Issues & $\begin{array}{l}\text { miss; girl; birth; widely; africa; gender; female; woman; age; } \\
\text { proportion; comparison; composition; india; comparable; unite }\end{array}$ & 8.19 & 7.73 \\
\hline 6 & Industrialization & $\begin{array}{l}\text { divergence; exception; late; structural; proportion; closely; } \\
\text { justification; comparable; difficult; industrialization; emphasize; } \\
\text { agriculture; respect; union; recently }\end{array}$ & 7.93 & 12.98 \\
\hline 7 & Input-Output Models & $\begin{array}{l}\text { requirement; sectoral; terminal; excess; input-output; full; revision; } \\
\text { capacity; series; create }\end{array}$ & 7.44 & 9.39 \\
\hline & $\begin{array}{l}\text { Equity \& } \\
\text { Consumption }\end{array}$ & consume; save; equity; retain; corporate & 7.35 & 3.87 \\
\hline
\end{tabular}

Table 18 - Thematic Analysis JEL Category “Q”

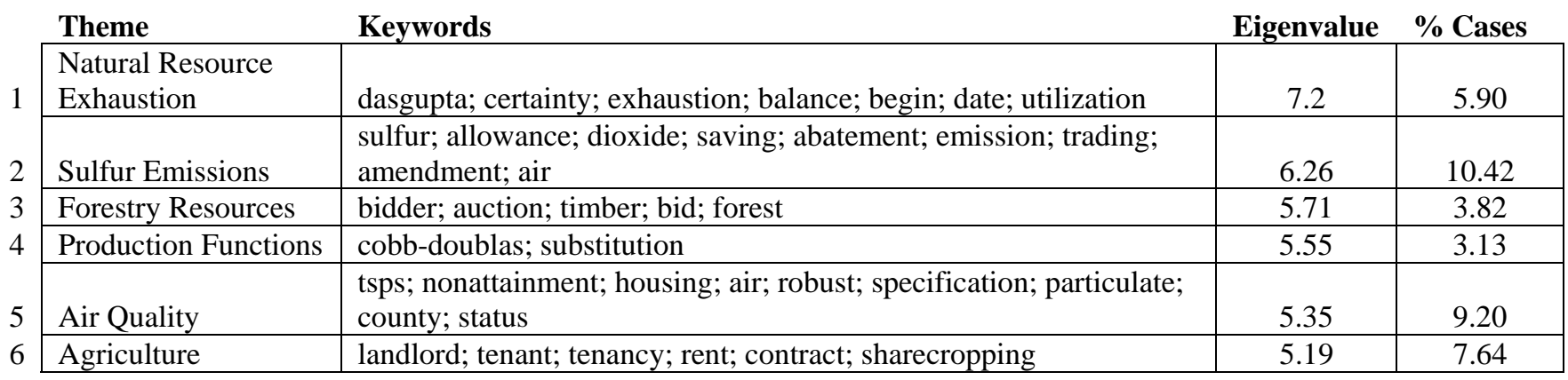


Table 19 - Thematic Analysis JEL Category “R”

Theme

1

1 Germany

Estimation

2

3

4

5

6

7
Keywords east; west; german; reunification; germany lasso; post-lasso; iv; conditional; expectation; procedure; validity; domain; sum; modification; normal; estimator; error; inference; perform

subgame; hotelling; game; simultaneously; solution; nonlinear; charge; pure transit; mode; trip; fare; auto; peak; automobile; travel; passenger; congestion; bay

school; nonwhite; peer; student; racial; socioeconomic; score; district

youth; male; man; poverty; young; reservation; participation; adult queue; delay; capacity; dominant; traffic; maximum

Eigenvalue \% Cases

\begin{tabular}{|l|l|}
\hline 38.52 & 2.26 \\
\hline & \\
8.35 & 7.61 \\
\hline 7.46 & 6.58 \\
\hline 6.73 & 6.17 \\
\hline 6.57 & 5.97 \\
\hline 6.29 & 5.35 \\
\hline 6.15 & 5.14 \\
\hline
\end{tabular}

\begin{tabular}{|l|l|}
\hline 38.52 & 2.26 \\
\hline & \\
8.35 & 7.61 \\
\hline 7.46 & 6.58 \\
\hline 6.73 & 6.17 \\
\hline 6.57 & 5.97 \\
\hline 6.29 & 5.35 \\
\hline 6.15 & 5.14 \\
\hline
\end{tabular}


Figure 2 - Network Analysis of JEL Codes, 1969-2014

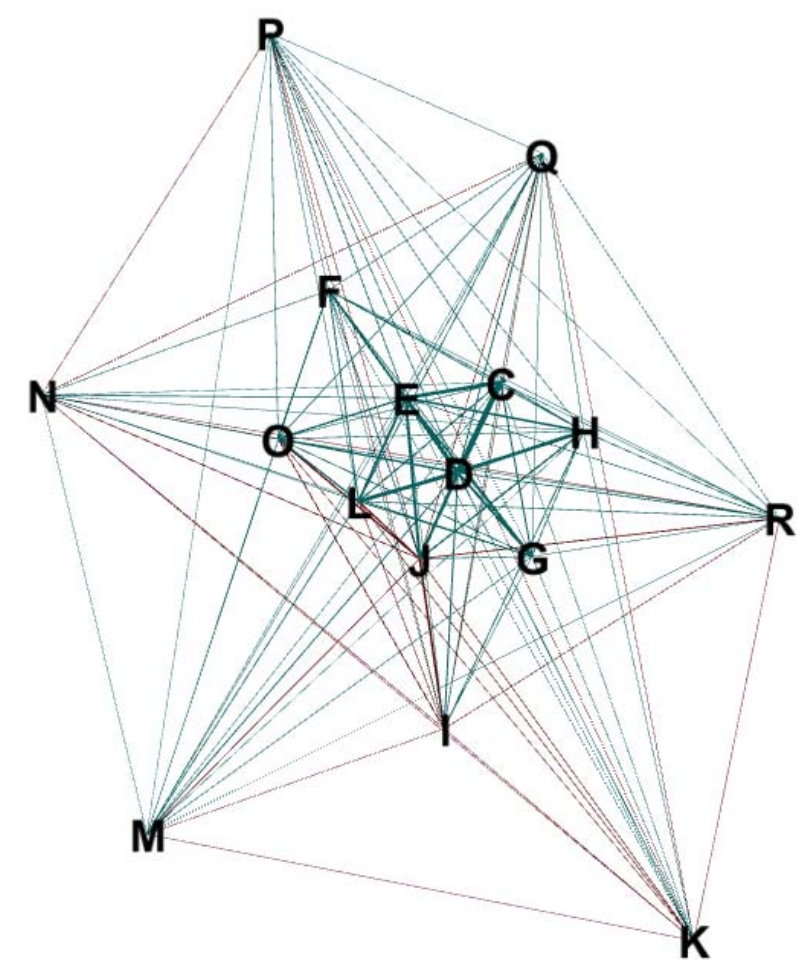


Table 20 - Network Analysis of JEL Categories (\%)

\begin{tabular}{|c|c|c|c|c|c|c|c|c|c|c|c|c|c|c|c|c|}
\hline & C & D & $\mathbf{E}$ & $\mathbf{F}$ & $\mathbf{G}$ & $\mathbf{H}$ & I & $\mathbf{J}$ & $\mathbf{K}$ & $\mathbf{L}$ & $\mathbf{M}$ & $\mathbf{N}$ & $\mathbf{O}$ & $\mathbf{P}$ & $\mathbf{Q}$ & $\mathbf{R}$ \\
\hline C & 12.9 & & & & & & & & & & & & & & & \\
\hline D & 5.78 & 9.62 & & & & & & & & & & & & & & \\
\hline $\mathbf{E}$ & 3.51 & 4.09 & 7.3 & & & & & & & & & & & & & \\
\hline $\mathbf{F}$ & 0.40 & 0.93 & 2.13 & 4.47 & & & & & & & & & & & & \\
\hline $\mathbf{G}$ & 1.02 & 2.33 & 1.81 & 0.54 & 2.34 & & & & & & & & & & & \\
\hline $\mathbf{H}$ & 0.71 & 3.42 & 1.90 & 0.61 & 0.54 & 1.82 & & & & & & & & & & \\
\hline I & 0.31 & 1.02 & 0.18 & 0.06 & 0.24 & 0.63 & 0.65 & & & & & & & & & \\
\hline $\mathbf{J}$ & 1.63 & 2.86 & 2.69 & 0.61 & 0.37 & 1.26 & 1.78 & 5.72 & & & & & & & & \\
\hline $\mathbf{K}$ & 0.09 & 0.45 & 0.02 & 0.05 & 0.13 & 0.12 & 0.12 & 0.32 & 0.37 & & & & & & & \\
\hline $\mathbf{L}$ & 1.01 & 3.77 & 2.29 & 0.88 & 1.04 & 0.52 & 0.26 & 1.13 & 0.30 & 1.73 & & & & & & \\
\hline $\mathbf{M}$ & 0.10 & 0.70 & 0.14 & 0.05 & 0.26 & 0.02 & 0.01 & 0.44 & 0.02 & 0.59 & 0.14 & & & & & \\
\hline $\mathbf{N}$ & 0.03 & 0.38 & 0.53 & 0.24 & 0.25 & 0.12 & 0.15 & 0.46 & 0.05 & 0.17 & 0.01 & 0.17 & & & & \\
\hline $\mathbf{O}$ & 0.30 & 1.65 & 1.41 & 1.10 & 0.58 & 0.31 & 0.59 & 1.39 & 0.17 & 1.31 & 0.10 & 0.29 & 0.73 & & & \\
\hline $\mathbf{P}$ & 0.30 & 0.43 & 0.54 & 0.17 & 0.09 & 0.20 & 0.05 & 0.20 & 0.03 & 0.17 & 0.01 & 0.10 & 0.28 & 0.55 & & \\
\hline $\mathbf{Q}$ & 0.21 & 0.81 & 0.41 & 0.30 & 0.17 & 0.24 & 0.09 & 0.25 & 0.04 & 0.57 & 0.02 & 0.18 & 0.52 & 0.11 & 1.07 & \\
\hline $\mathbf{R}$ & 0.19 & 0.62 & 0.38 & 0.12 & 0.15 & 0.44 & 0.18 & 0.69 & 0.09 & 0.43 & 0.05 & 0.13 & 0.25 & 0.05 & 0.14 & 0.65 \\
\hline
\end{tabular}


Figure 3 - Network Analysis of Top Themes, 1969-2014

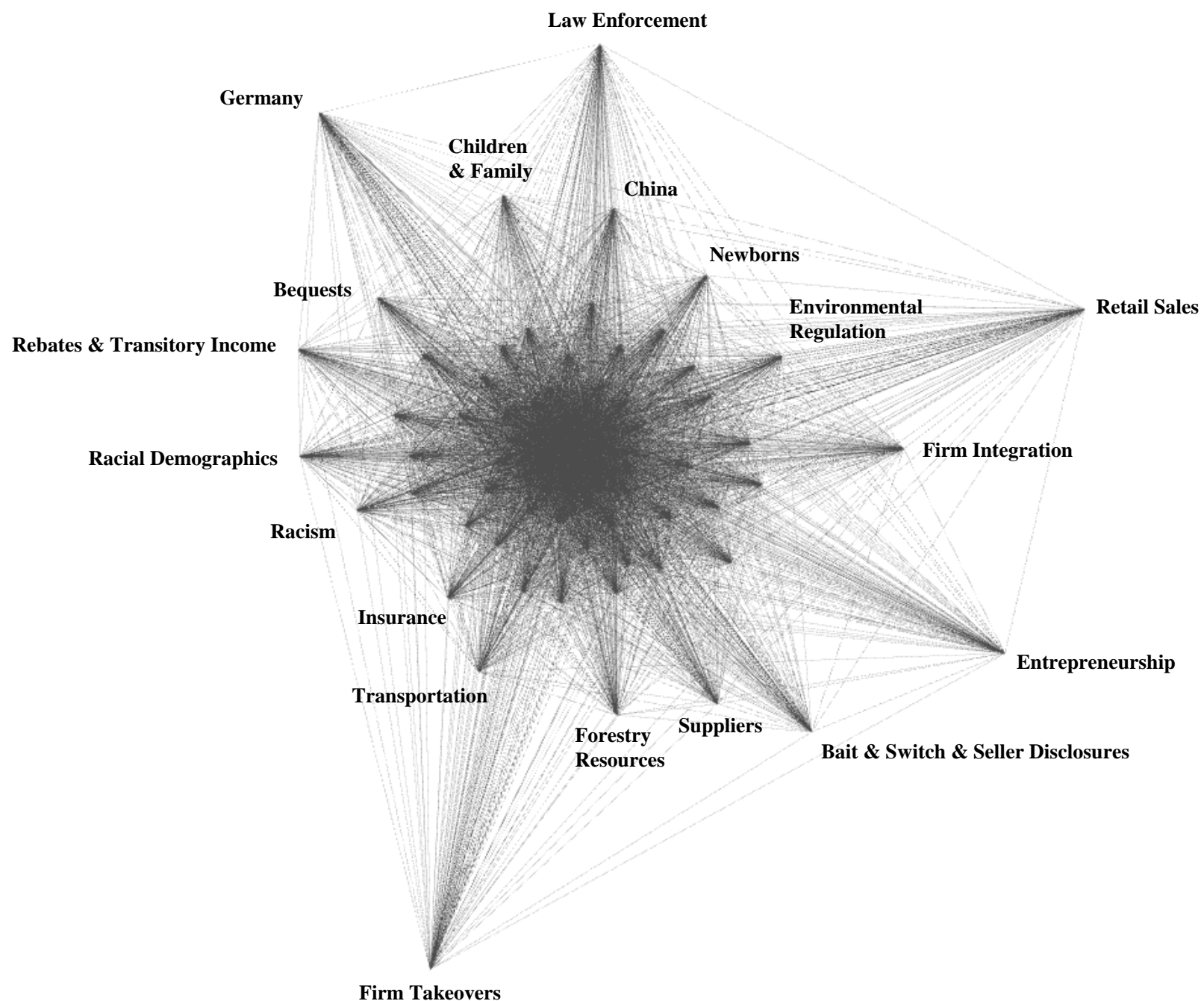




\section{Appendix A: \\ JEL Code Matching Strategy}

\begin{tabular}{|c|c|c|}
\hline Subject & $\begin{array}{l}\text { post-1990 JEL } \\
\text { subject code }\end{array}$ & pre-1990 JEL subject code \\
\hline General Economics \& Teaching & $\mathrm{A}$ & $011,012,110,115$ \\
\hline $\begin{array}{l}\text { History of Economic Thought, Methodology, \& Heterodox } \\
\text { Approaches }\end{array}$ & B & 031, 036, 316-318, 329, 360 \\
\hline Mathematical \& Quantitative Methods & $\mathrm{C}$ & $\begin{array}{l}021,026,210-215,220,222,229,260- \\
262,2110,2112-2120,2130,2132-2135 \\
2140,2150,2200,2220,2270,2290\end{array}$ \\
\hline Microeconomics & $\mathrm{D}$ & $\begin{array}{l}020,022,024,025,114,200,224,225, \\
227,228,240,242-244,250-252,511- \\
513,522,600,921,1140,2240,2280, \\
5110,5120,5130,5131,5220,9210-9213\end{array}$ \\
\hline Macroeconomics \& Monetary Economics & $\mathrm{E}$ & $\begin{array}{l}023,112,120-124,130-134,221,223, \\
226,230-235,239,311,1120,1210, \\
1211,1213-1217,1221,1223,1224, \\
\text { 1228, 1230, 1243, 1244, 1310, 1312, } \\
\text { 1313, 1320, 1322-1324, 1330-1332, } \\
\text { 2340, 1342, 2210, 2212, 2213, 2230, } \\
2260,3110,3112,3116\end{array}$ \\
\hline International Economics & $\mathrm{F}$ & $\begin{array}{l}111,400,411,420-423,431-433,441- \\
443,1110,1112,4000,4110,4112-4114, \\
\text { 4200, 4210, 4220, 4230, 4232, 4233, } \\
\text { 4310, 4312-4314, 4320, 4330, 4410- } \\
4412,4420,4430\end{array}$ \\
\hline Financial Economics & G & $\begin{array}{l}310,312-315,521,3120,3130-3132 \\
3140,3150-3153,5200,5210\end{array}$ \\
\hline Public Economics & $\mathrm{H}$ & $\begin{array}{l}\text { 320-325, 641, 915, 3200, 3210, 3212, } \\
\text { 3216, 3220, 3221, 3226, 3228, 3230, } \\
\text { 3240-3243, 3250, 6410, 9150 }\end{array}$ \\
\hline Health, Education, and Welfare & I & $\begin{array}{l}\text { 911, 913, 914, 9100, 9110, 9130, 9140, } \\
9300\end{array}$ \\
\hline Labor and Demographic Economics & $\mathrm{J}$ & $\begin{array}{l}\text { 811-813, 820-826, 831-833, 841, 850, } \\
\text { 851, 912, 917, 918, 8110, 8120, 8130- } \\
\text { 8135, 8210, 8220-8226, 8230, 8240- } \\
\text { 8243, 8250, 8260, 8300, 8310, 8320- } \\
\text { 8322, 8330-8332, 8410, 8510, 9120, } \\
\text { 9170, 9180 }\end{array}$ \\
\hline Law and Economics & $\mathrm{K}$ & 916,9160 \\
\hline Industrial Organization & $\mathrm{L}$ & $\begin{array}{l}\text { 514, 610-616, 619, 620, 631-636, 5140, } \\
\text { 6110, 6120, 6130, 6140, 6150, 6160, } \\
\text { 6190, 6300, 6310, 6312-6318, 6320, } \\
\text { 6322, 6323, 6333, 6340, 6352-6358, } 6360\end{array}$ \\
\hline $\begin{array}{l}\text { Business Administration \& Business Economics; Marketing; } \\
\text { Accounting }\end{array}$ & $\mathrm{M}$ & $531,541,5310,5410$ \\
\hline Economic History & $\mathrm{N}$ & $\begin{array}{l}\text { 041-048, 410-412, 420, 430, 440, 450- } \\
452,463,470,473\end{array}$ \\
\hline Economic Development, Technological Change, \& Growth & $\mathrm{O}$ & $621,718,6210-6212,7180$ \\
\hline Economic Systems & $\mathrm{P}$ & $\begin{array}{l}027,050-053,113,270-272,500,510 \\
520,530,1113,1114,1130,1132,1136\end{array}$ \\
\hline $\begin{array}{l}\text { Agricultural \& Natural Resource Economics; Environmental \& } \\
\text { Ecological Economics }\end{array}$ & $\mathrm{Q}$ & $\begin{array}{l}\text { 710-717, 721-723, 7100, 7110, 7120, } \\
\text { 7130, 7140, 7150, 7151, 7160, 7170- } \\
7172,7210,7211,7220,7230\end{array}$ \\
\hline Regional, Real Estate, and Transportation Economics & $\mathrm{R}$ & $\begin{array}{l}\text { 731, 931-933, 941, 2250, 7310, 9310, } \\
\text { 9320, 9330, 9410-9413 }\end{array}$ \\
\hline
\end{tabular}




\section{References}

1. Antweiler, Werner and Murray Z. Frank. 2004. "Is All That Talk Just Noise? The Information Content of Internet Stock Message Boards.” The Journal of Finance 59(3):1259-1294.

2. Baker, Scott R., Nicholas Bloom, Brandice Canes-Wrone, Steven J. Davis, and Jonathan Rodden. 2014. "Why Has US Policy Uncertainty Risen Since 1960?” American Economic Review: Papers \& Proceedings 104(5):56-60.

3. Card, David and Stefano DellaVigna. 2013. "Nine Facts About Top Journals in Economics.” Journal of Economic Literature 51(1):144-161.

4. Cherrier, Beatrice. 2015. “Classifying Economics: A History of the JEL Codes.” Working Paper.

5. Cropper, Maureen L. 2000. "Has Economic Research Answered the Needs of Environmental Policy?” Journal of Environmental Economics and Management 39:328350.

6. Durden, Garey C., and Larry V. Ellis. 1993. "A Method for Identifying the Most Influential Articles in an Academic Discipline.” Atlantic Economic Journal 21(4):1-10.

7. Engemann, Kristie M., and Howard J. Wall. 2009. “A Journal Ranking for the Ambitious Economist.” Federal Reserve Bank of St. Louis Review 91(3):127-139.

8. Gentzkow, Matthew and Jesse M. Shapiro. 2010. "What Drives Media Slant? Evidence from U.S. Daily Newspapers.” Econometrica 78(1):35-71.

9. Goyal, Sanjeev, Marco J. van der Leij, and Jose L. Moraga-Gonzalez. 2006. "Economics: An Emerging Small World.” Journal of Political Economy 114(2):403-412.

10. Grijalva, Therese, and Clifford Nowell. 2014. "What Interests Environmental and Resource Economists? A Comparison of Research Output in Agricultural Economics versus Environmental Economics.” Agricultural and Resource Economics Review 43(2):209-226.

11. Hamermesh, Daniel S. 2014. “Age, Cohort, and Co-Authorship.” Working Paper.

12. Hamermesh, Daniel S. 2013. "Six Decades of Top Economics Publishing: Who and How?” Journal of Economic Literature 51(1):162-172.

13. Jacomy, Mathieu, Tommaso Venturini, Sebastien Heymann, and Mathieu Bastian. 2014. "ForceAtlas2, a Continuous Graph Layout Algorithm for Handy Network Visualization Designed for the Gephi Software.” PLoS ONE 9(6): e98679. 
14. Kalaitzidakis, Pantelis, Theofanis P. Mamuneas, and Thanasis Stengos. 2001. "Rankings of Academic Journals and Institutions in Economics.” Working Paper.

15. Kelly, Michael A. and Stephen Bruestle. 2011. “Trend of Subjects Published in Economics Journals 1969-2007.” Economic Inquiry 49(3):658-673.

16. Kim, E. Han, Adair Morse, and Luigi Zingales. 2006. "What Has Mattered to Economics Since 1970.” The Journal of Economic Perspectives 20(4):189-202.

17. Kolstad, Charles. 2010. Environmental Economics, $2^{\text {nd }}$ Edition. Oxford University Press.

18. Kosnik, L-R. 2015a. "In Tandem or Out of Sync? Academic Economics Research and Public Policy Measures.” Contemporary Economic Policy In Press.

19. Kosnik, L-R. 2015b. "What Have Economists Been Doing for the Last 50 Years? A Text Analysis of Published Academic Research from 1960-2010.” Economics 9:1-38.

20. Kosnik, L-R. 2014. “Determinants of Contract Completeness: An Environmental Regulatory Application.” International Review of Law and Economics 37:198-208.

21. Laband, David N., and Robert D. Tollison. 2000. “Intellectual Collaboration.” Journal of Political Economy 108(3):632-662.

22. Laband, David N., Robert D. Tollison, and Gokhan Karahan. 2002. “Quality Control in Economics.” Kyklos 55:315-334.

23. Perman, Roger, Yue Ma, Michael Common, Daivd Maddison, and James Mcgilvray. 2012. Natural Resource and Environmental Economics, $4^{\text {th }}$ Edition. Prentice Hall.

24. Rath, Katharina, and Klaus Wohlrabe. 2015. "Recent Trends in Co-Authorship in Economics: Evidence from RePEc.” CESifo Working Paper No. 5492.

25. Rosell, Carlos, and Ajay Agrawal. 2009. "Have University Knowledge Flows Narrowed? Evidence from Patent Data.” Research Policy 38:1-13.

26. Rummel, R.J. Applied Factor Analysis. Evanston, ILL: Northwestern University Press.

27. Tetlock, Paul C. 2007. “Giving Content to Investor Sentiment: The Role of Media in the Stock Market.” Journal of Finance 62(3):1139-1168.

28. Tietenberg, Tom, and Lynne Lewis. 2012. Environmental \& Natural Resource Economics, $9^{\text {th }}$ Edition. Prentice Hall.

29. Weterings, Anet, and Rokerik Ponds. 2009. "Do Regional and Non-Regional Knowledge Flows Differ? An Empirical Study on Clustered Firms in the Dutch Life Sciences and Computing Services Industry." Industry and Innovation 16(1):11-31. 
30. Whaples, Robert. 1991. "A Quantitative History of the Journal of Economic History and the Cliometric Revolution.” The Journal of Economic History 51(2):289-301. 